\title{
Unworthy peer review process and publishing method
}

\author{
Mehdi Dadkhah, ${ }^{1}$ Giorgio Bianciardi ${ }^{2}$ \\ ${ }^{1}$ Independent Information Science Scientist, Isfahan, Iran; ${ }^{2}$ Department of Medical Biotechnology, University of Siena, Italy
}

To the Editor,

In recent years, many questionable journals have appeared and their number has been increasing at a steady pace. ${ }^{1}$ These journals have questionable peer review systems which do not respect adequate standards of reviewing and publishing and sometimes they seem more focused on charging publication fees than on the quality of manuscripts. Such questionable journals are also called predatory journals. This definition has been introduced for the first time in the academic world by Jeffrey Beall, an associate professor in Auraria Library, University of Colorado, Denver, USA. ${ }^{2}$ He proposed a list of predatory publishers and journals, and developed 52 criteria for inclusion in that list. Predatory journals usually publish papers without a peer review or use peer review processes of low quality. So far unsuitable peer review processes have become the most important criterion for identifying predatory journals. ${ }^{3}$ Fortunately many papers discuss the problem of predatory journals and general guidelines for detecting them are now available., ${ }^{4,5}$

In this commentary, we introduce the concept of $u n$ worthy peer review process as an opposite publishing method. We define unworthy peer review processes the phenomenon of editors who accept or reject papers without appropriate comments. Recently we have been facing different unworthy peer review processes. Some-

Correspondence: Mehdi Dadkhah, Independent Information Science Scientist, Isfahan, Iran.

E-mail: Dadkhah1992@gmail.com

Key words: Unworthy peer review process; predatory journals; ethics.

Received for publication: 24 June 2016.

Revision received: 16 September 2016.

Accepted for publication: 14 October 2016.

This work is licensed under a Creative Commons Attribution NonCommercial 4.0 License (CC BY-NC 4.0).

CCopyright M. Dadkhah and G. Bianciardi, 2017

Licensee PAGEPress, Italy

Italian Journal of Medicine 2017; 11:82-83

doi:10.4081/itjm.2016.754 times editors search for authors' previous papers and curricula vitae (CV) and publish papers on such criterion. That means that some journals preferentially publish papers, which had been submitted by authors who have good publication histories, without any judgment about the quality of their content. In other words, they evaluate the authors' CV before starting a peer review of a manuscript and stop there. The evaluation of an authors' CV instead of peer reviewing a paper is an unethical method that is often used for papers classified as opinions or commentaries.

That contrasts with the written principles for editors reported by The Committee of Publication Ethics (COPE) according to which all editors should respect and consider for each submitted paper (http://publicationethics.org/files/Code_of_conduct_for_journal_editors_Mar11.pdf). Moreover, other committee of journals editors (such as the International Committee of Medical Journal Editors) wrote strict directives such as the Responsibilities in the Submission and Peer-Review Process (http://www.icmje.org/recommendations/browse/roles-and-responsibilities/responsibilitiesin-the-submission-and-peer-peview-process.html).

According to our inspection, all journals which use this kind of unworthy peer review process are indexed in scientific databases such as Scopus or Thomson Reuters Web of Science but they rank low in comparison to other journals. Editors may consider that publishing papers authored by well-known researchers might improve citations and that such unworthy peer review process be helpful to climb up the ranking of scientific databases.

Unfortunately, unworthy processes are not limited to peer review. Some journals adopt questionable publishing methods, too. To prevent authors from withdrawing a paper after it has been submitted, they impose withdrawal charges, which are higher than the standard publication charges. Authors are led to think that their papers will not be published without paying these publication charges. Actually, most of such journals do not receive enough papers to complete the scheduled issues and they would publish all received papers anyway.

A third type of unworthy peer review process is related to the limitation in the reviewer selection 
process. Some editors cannot find suitable reviewers to evaluate a specific paper. Instead of wasting time in searching a suitable reviewer, those editors reject papers with unrelated comments such as style and formatting problems or, on the opposite, they publish the paper because of authors' previous researches and CV.

All those conditions remind to an Iranian expression $a$ whey work. Iranian people use this expression to indicate a work or process that is done in a weird way. So, we can name this type of peer review and publishing process as the Whey reviewing and publishing methods. In English literature, we have a similar proverb, which reflects similar means When the shit hits the fan (http://dictionary.cambridge.org/dictionary/english/shit-hits-the-fan).

Whey peer review and publishing processes raise new warnings in the scholarly publishing world and may led to potential issues in academic integrity. If the peer review process is replaced with $\mathrm{CV}$ evaluation or other criteria, which are not related to the content of the paper, the number of fake and bogus research publications will probably increase. Journals must have a transparent peer review process and a clear publishing method, focused on the quality of the scientific content and independent from the academic reputation of authors. Fortunately, most journals follow international standards in reviewing and publishing. Our attention should concentrate on those that do not.

\section{References}

1. Günaydin GP, Dogan NÖ. A growing threat for academicians: fake and predatory journals. J Acad Emerg Med 2015; $14: 94$.

2. Beall J. Medical publishing triage-chronicling predatory open access publishers. Ann Med Surg 2013;2:47-9.

3. Dadkhah M, Bianciardi G. Ranking predatory journals: solve the problem instead of removing it!. Adv Pharm Bull 2016;6:1-4.

4. Moher D, Moher E. Stop predatory publishers now: act collaboratively. Ann Intern Med 2016;164:616-7.

5. Roberts J. Predatory journals: think before you submit. Headache 2016;56:618-21. 